\title{
A systematic analysis and comparison of the dispersion curves of hypocycloidal and elliptical Bragg waveguide using very simple analytical method
}

\author{
Chandra Kamal Borgohain ${ }^{1}$, Chakresh Kumar ${ }^{2}$ \\ ${ }^{1}$ Department of Electronics and Communication Engineering, Tezpur (central) University, INDIA \\ ${ }^{2}$ University School of Information \& Communication Technology, Guru Gobind Singh Indraprastha University, Dwarka, New Delhi- \\ 110078, India
}

Email address:

borgohainchandrakama1176@gmail.com (C. K. Borgohain)

To cite this article:

Chandra Kamal Borgohain, Chakresh Kumar. A Systematic Analysis and Comparison of the Dispersion Curves of Hypocycloidal and Elliptical Bragg Waveguide Using very Simple Analytical Method. American Journal of Electromagnetics and Applications.

Vol. 2, No. 1, 2014, pp. 1-10. doi: 10.11648/j.ajea.20140201.11

\begin{abstract}
In this paper we have analyzed the modal dispersion characteristics of two unconventional Bragg waveguides namely hypocycloidal and elliptical Bragg waveguide by the use of very simple matrix method. We are using matrix equation which replaces the boundary condition. We obtained the characteristic equation analytically. In both cases all the outputs are showing in the form of dispersion curves and we are also trying to compare their dispersion characteristics. It is seen that in case of hypocycloidal Bragg waveguide [1] the cut off frequency increases with the decrease of cladding layers .But in case of elliptical Bragg waveguide [2], when the cladding layer decreases from six layered to four layered the cutoff frequency increases and from four layer to two layer the cutoff frequency become decreases.
\end{abstract}

Keywords: Cutoff Number (V), Normalized Propagation Constant (b), Weak Guidance

\section{Introduction}

Now a day's Bragg waveguide replaces the conventional optical waveguides where guiding of light takes place via Bragg reflection.Here refractive index of the core is lower than the cladding regions that surround it $[3,4]$. We know that in conventional transmission of light waves through optical waveguide is guided by the phenomena of total internal reflection (TIF).In this sort of waveguide the refractive index of the core is higher compared to the claddings that surround it. Because of the perfection of the TIF no other losses occur except some absorption and scattering losses. Bragg waveguides are reliable and advantageous in compared to other conventional optical fibers in a sense that here core is guided by air therefore by the transmission of light through Bragg fibers some nonlinear effects can be easily minimized. In case of Bragg fibers we can get truly single guided mode which is not possible for a conventional fiber. This concept helps the Bragg fiber to work as a mode filter. Bragg fiber eliminates some undesirable effects that are dependent on polarization. By the use of optical waves atom guiding is possible in case of Bragg fiber [10].It brings the concept of photonic band gap which is a topic of recent interest [5-8].

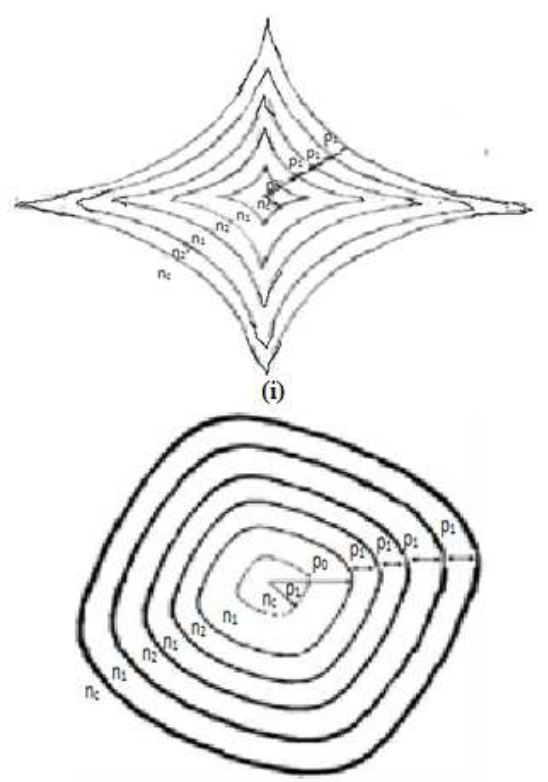

(ii)

Fig 1. (i) Cross-section of a hypocycloidal Bragg waveguide. (ii) Crosssection of an elliptical Bragg waveguide. 
In one sense we can say this as photonic band gap Bragg fibers $[8,9]$.Finally we can say that transmission of optical wave through Bragg fiber makes the optical transmission process more reliable as well as efficient. In this present paper we are trying to analyze two Bragg waveguides, hypocycloidal Bragg waveguide Fig.1 (i) and a elliptical Bragg waveguide Fig. 1(ii) which are not conventional. The details of the procedure and analysis are given below. At the end of this paper we are also trying to make a comparison between them.

\section{Theoretical Approach}

We are considering the unconventional Bragg waveguide having hypocycloidal core cross section and an unconventional Bragg waveguide having elliptical core cross-section shown in Fig.1(i) and Fig.1(ii) respectively. The two diagrams are given for comparison purposes.

\subsection{Hypocycloidal Bragg Waveguide}

\subsubsection{Eigen Value Equation}

We have analyzed the simple matrix method [1] to determine the modal characteristics of a hypocycloidal Bragg waveguide. Where by using the matrix equation we are trying to replace the boundary condition. For a six layered Bragg waveguide the cross sectional view is shown in Fig. 1(i).with low refractive index $\left(n_{c}\right)$ in the core and higher refractive indices $n_{1}$ and $n_{2}\left(n_{1}>n_{2}\right)$ in the cladding regions around the core. By this we have designed a Bragg waveguide having claddings with alternate high and low refractive indices. The index profile for the considered structure is given below

$$
\mathrm{n}(\mathrm{m})=\left(\begin{array}{ll}
\mathrm{n}_{\mathrm{c}} ; & 0<\mathrm{m}<\mathrm{m}_{1} \\
\mathrm{n}_{1} ; & \mathrm{m}_{1}<\mathrm{m}<\mathrm{m}_{2} \\
\mathrm{n}_{2} ; & \mathrm{m}_{2}<\mathrm{m}<\mathrm{m}_{3} \\
\mathrm{n}_{1} ; & \mathrm{m}_{3}<\mathrm{m}<\mathrm{m}_{4} \\
\mathrm{n}_{2} ; & \mathrm{m}_{4}<\mathrm{m}<\mathrm{m}_{5} \\
\mathrm{n}_{1} ; & \mathrm{m}_{5}<\mathrm{m}<\mathrm{m}_{6} \\
\mathrm{n}_{\mathrm{c}} ; & \mathrm{m}>\mathrm{m}_{6}
\end{array}\right)
$$

$$
\begin{gathered}
\left(4 \varrho^{8 / 3} / \varrho^{8 / 3}-\eta^{8 / 3}\right)\left(d^{2} E_{z} / d \varrho^{2}\right)-\left\{4 \varrho^{5 / 3}\left(\varrho^{8 / 3}+3 \eta^{8 / 3}\right) / 3\left(\varrho^{8 / 3}-\eta^{8 / 3}\right)^{2}\right\} \\
\left(d E_{z} / d \varrho\right)+(\varrho / \eta)^{2 / 3}\left(d^{2} E_{z} / d \eta^{2}\right)-\left\{\varrho^{2 / 3}\left(\varrho^{8 / 3}+3 \eta^{8 / 3}\right) / 3 \eta^{5 / 3}\left(\varrho^{8 / 3}-\eta^{8 / 3}\right)\right\}\left(d E_{z} / d \eta\right)+u^{2} E_{z}=0
\end{gathered}
$$

$\mathrm{H}_{\mathrm{z}}$.

Again we have a similar equation for the magnetic field

We have, $u^{2}=\omega^{2} \varepsilon_{1} \mu_{1}-\beta^{2}$,

Where,

$\omega$ - Angular frequency.

$\varepsilon_{1}$ - permittivity of the guiding region.

$$
4\left(d^{2} E_{z} / d \varrho^{2}\right)-(4 / 3 \varrho)\left(d E_{z} / d \varrho\right)+(\varrho / \eta)^{2 / 3}\left(d^{2} E_{z} / d \eta^{2}\right)-\left(\varrho^{2 / 3} / 3 \eta^{5 / 3}\right)\left(d E_{z} / d \eta\right)+u^{2} E_{z}=0
$$

By the separation of variable concept, we can obtain

$$
E_{z}=E_{11}(\varrho) E_{22}(\eta) \exp (j(\omega t-\beta z)
$$


For our proposed consideration, the longitudinal components of the E field can be written as

$$
\begin{gathered}
E_{\mathrm{z} 11}=\left(\mathrm{U}_{\mathrm{i}} \varrho\right)^{2 / 3} \mathrm{MJ}_{2 / 3}\left(\mathrm{U}_{\mathrm{i}} \varrho \mathrm{d}\right) \mathrm{F}(\eta) \exp (\mathrm{j}(\omega \mathrm{t}-\beta \mathrm{z}) \\
\mathrm{E}_{\mathrm{z} 12}=\left(\mathrm{U}_{\mathrm{i}} \varrho\right)^{2 / 3} \mathrm{NY}_{2 / 3}\left(\mathrm{U}_{\mathrm{i}} \varrho \mathrm{d}\right) \mathrm{F}(\eta) \exp (\mathrm{j}(\omega \mathrm{t}-\beta \mathrm{z}) \\
\mathrm{E}_{\mathrm{z} 1}=\mathrm{E}_{\mathrm{z} 11}+\mathrm{E}_{\mathrm{z} 12}
\end{gathered}
$$

Now, for the even modes we can have the longitudinal component of the $\mathrm{E}$ field $\mathrm{E}_{\mathrm{z} 1}$ as

$$
\begin{gathered}
\mathrm{E}_{\mathrm{core}}=\mathrm{E}_{\mathrm{z} 1} \\
\mathrm{E}_{\text {core }}=\left(\mathrm{U}_{\mathrm{i}} \varrho\right)^{2 / 3}\left[\mathrm{MJ}_{2 / 3}\left(\mathrm{U}_{\mathrm{i}} \varrho \mathrm{d}\right)+\mathrm{NY}_{2 / 3}\left(\mathrm{U}_{\mathrm{i}} \varrho \mathrm{d}\right)\right] \mathrm{F}(\eta) \exp (\mathrm{j}(\omega \mathrm{t}-\beta \mathrm{z}) \\
\mathrm{H}_{\mathrm{z} 11}=\left(\mathrm{U}_{\mathrm{i}} \varrho\right)^{2 / 3} \mathrm{OJ}_{2 / 3}\left(\mathrm{U}_{\mathrm{i}} \varrho \mathrm{d}\right) \mathrm{F}(\eta) \exp (\mathrm{j}(\omega \mathrm{t}-\beta \mathrm{z}) \\
\mathrm{H}_{\mathrm{z} 12}=\left(\mathrm{U}_{\mathrm{i}} \varrho\right)^{2 / 3} \mathrm{PY}_{2 / 3}\left(\mathrm{U}_{\mathrm{i}} \varrho \mathrm{d}\right) \mathrm{F}(\eta) \exp (\mathrm{j}(\omega \mathrm{t}-\beta \mathrm{z}) \\
\mathrm{H}_{\mathrm{z} 1}=\mathrm{H}_{\mathrm{z} 11}+\mathrm{H}_{\mathrm{z} 12}
\end{gathered}
$$

Now, for the even modes we can have the longitudinal component of the $\mathrm{H}$ field $\mathrm{H}_{\mathrm{zl}}$

$$
\mathrm{H}_{\text {core }}=\mathrm{H}_{\mathrm{z} 1}
$$

$\mathrm{H}_{\text {core }}=\left(\mathrm{U}_{\mathrm{i}} \mathrm{\varrho}\right)^{2 / 3}\left[\mathrm{OJ}_{2 / 3}\left(\mathrm{U}_{\mathrm{i}} \varrho \mathrm{d}\right)+\mathrm{PY}_{2 / 3}\left(\mathrm{U}_{\mathrm{i}} \mathrm{\varrho} \mathrm{d}\right)\right] \mathrm{F}(\eta) \exp (\mathrm{j}(\omega \mathrm{t}-\beta \mathrm{z})(14)$

Where ,

$$
\mathrm{U}_{\mathrm{i}}^{2}=\mathrm{k}_{0}^{2} \mathrm{n}_{\mathrm{i}}^{2}-\beta^{2},
$$

For $\mathrm{i}=1,2$, the corresponding refractive indices are $\mathrm{n}_{1}$ and $\mathrm{n}_{2}$.Again we can have the solution for core and the outer most region as

$$
\begin{aligned}
& E_{z 21}=(w \varrho)^{2 / 3} Q_{2 / 3}(w \varrho d) F(\eta) \exp (j(\omega t-\beta z) \\
& E_{z 22}=(w \varrho)^{2 / 3} R_{2 / 3}(w \varrho d) F(\eta) \exp (j(\omega t-\beta z) \\
& E_{\text {cladd }}=E_{z 21}+E_{z 22} \\
& E_{\text {cladd }}=(w \varrho)^{2 / 3}\left[Q_{2 / 3}(w \varrho d)+R_{2 / 3}(w \varrho d)\right] F(\eta) \exp (j(\omega t-\beta z) \\
& (\text { for cladding) } \\
& H_{z 21}=(w \varrho)^{2 / 3} S_{2 / 3}(w \varrho d) F(\eta) \exp (j(\omega t-\beta z) \\
& H_{z 22}=(w \varrho)^{2 / 3} \mathrm{TK}_{2 / 3}(w \varrho d) F(\eta) \exp (j(\omega t-\beta z) \\
& H_{z 2}=H_{z 21}+H_{z 22} \\
& H_{\text {cladd }}=H_{z 2} \\
& H_{\text {cladd }}=(w \varrho)^{2 / 3}\left[S_{2 / 3}(w \varrho d)+T K_{2 / 3}(w \varrho d)\right] F(\eta) \exp (j(\omega t-\beta z) \\
& \text { Where } w^{w}=\sqrt{\beta^{2}-k_{0}^{2} n_{c}^{2} \text {, }} \\
& n_{c}-\text { common refractive index . } \\
& J_{2 / 3}-\text { Bessel functions of first kind. } \\
& Y_{2 / 3}-\text { Bessel functions of second kind. }
\end{aligned}
$$

$\mathrm{I}_{2 / 3} \& \mathrm{~K}_{2 / 3}$ - modified Bessel functions.

$\beta$ - Axial component of propagation vector.

$\omega$ - Wave frequency.

$\mu$-permeability of non-magnetic medium

$\varepsilon_{1}$ - permittivity of the core.

$\varepsilon_{2}$ - permittivity of the cladding region

$\mathrm{d}=\frac{1}{2}$ (emerging due to peculiarity of the geometrical shape)

$\mathrm{M}, \mathrm{N}, \mathrm{O}, \mathrm{P}, \mathrm{Q}, \mathrm{R}, \mathrm{S}$ and $\mathrm{T}$ are all constants and these are unknown.

Boundary conditions for the above Bragg waveguide consideration

$$
\begin{gathered}
\left.\mathrm{E}_{\text {core }}\right|_{\mathrm{m}}=\left.\mathrm{E}_{\text {Cladd }}\right|_{\mathrm{m}} \\
\left.\frac{\partial \text { Ecore }}{\partial \varrho}\right|_{\mathrm{m}}=\left.\frac{\partial \text { Ecladd }}{\partial \varrho}\right|_{\mathrm{m}}
\end{gathered}
$$

By analytically solving this equation we get equations which contain twenty two unknown constants. Then we put in a $12 \times 12$ matrix[1]. The determinant formed by this matrix is $\operatorname{det}[i]$.We can get the nontrivial solution only when

$$
\operatorname{det}[\mathrm{i}]=0
$$

\subsection{Elliptical Bragg Waveguide}

The index profile for elliptical is similar with the previous case. This can be written as

$$
\mathrm{n}(\mathrm{m})=\left(\begin{array}{ll}
\mathrm{n}_{\mathrm{c}} ; & 0<\mathrm{m}<\mathrm{m}_{1} \\
\mathrm{n}_{1} ; & \mathrm{m}_{1}<\mathrm{m}<\mathrm{m}_{2} \\
\mathrm{n}_{2} ; & \mathrm{m}_{2}<\mathrm{m}<\mathrm{m}_{3} \\
\mathrm{n}_{1} ; & \mathrm{m}_{3}<\mathrm{m}<\mathrm{m}_{4} \\
\mathrm{n}_{2} ; & \mathrm{m}_{4}<\mathrm{m}<\mathrm{m}_{5} \\
\mathrm{n}_{1} ; & \mathrm{m}_{5}<\mathrm{m}<\mathrm{m}_{6} \\
\mathrm{n}_{\mathrm{c}} ; & \mathrm{m}>\mathrm{m}_{6}
\end{array}\right)
$$

Where,

$$
\begin{aligned}
& \mathrm{m}_{1}=\mathrm{p}_{1 ;} \\
& \mathrm{m}_{2}=\mathrm{p}_{0} ; \\
& \mathrm{m}_{3}=\mathrm{p}_{0}+\mathrm{p}_{1} ; \\
& \mathrm{m}_{4}=\mathrm{p}_{0}+2 \mathrm{p}_{1} ; \\
& \mathrm{m}_{5}=\mathrm{p}_{0}+3 \mathrm{p}_{1} ; \\
& \mathrm{m}_{6}=\mathrm{p}_{0}+4 \mathrm{p}_{1} ;
\end{aligned}
$$

The general equation for the elliptical structure can be written as

$$
x^{4}+y^{4}=6^{4}
$$

The equation for the curve which is normal to eq (23), we can write it as

$$
1 / x^{2}-1 / y^{2}=1 / f^{2}
$$

We have chosen new coordinates $(\xi, \eta, z)$ sufficient for our considered geometry and we make an assumption that 
electromagnetic wave propagates along the z-direction. Now, we can get the expressions for electric and magnetic field in terms of our new coordinate considered by using the Maxwell equations [12]. Where for even modes $\mathrm{E}_{\mathrm{zl}}(\xi)$ and $\mathrm{H}_{\mathrm{z} 1}(\xi)$ are the longitudinal field components.

We can write different field components as,

$\mathrm{E}_{11}(\xi)=\frac{1}{\xi} \mathrm{AJ}_{1}\left(\mathrm{U}_{\mathrm{i}} \mathrm{d} \xi\right)$

$\mathrm{E}_{12}(\xi)=\frac{1}{\xi} \mathrm{BY}_{1}\left(\mathrm{U}_{\mathrm{i}} \mathrm{d} \xi\right)$

$\mathrm{E}_{\mathrm{z} 1}(\xi)=\mathrm{E}_{11}(\xi)+\mathrm{E}_{12}(\xi)$

$\mathrm{E}_{\mathrm{z} 1}(\xi)=\mathrm{E}_{\text {core }}(\xi)=\frac{1}{\xi}\left[\mathrm{AJ}_{1}\left(\mathrm{U}_{\mathrm{i}} \mathrm{d} \xi\right)+\mathrm{BY}_{1}\left(\mathrm{U}_{\mathrm{i}} \mathrm{d} \xi\right)\right.$

$\mathrm{H}_{11}(\xi)=\frac{1}{\xi} \mathrm{CJ}_{1}\left(\mathrm{U}_{\mathrm{i}} \mathrm{d} \xi\right)$

$\mathrm{H}_{12}(\xi)=\frac{1}{\xi} \mathrm{DY} \mathrm{Y}_{1}\left(\mathrm{U}_{\mathrm{i}} \mathrm{d} \xi\right)$

$\mathrm{H}_{\mathrm{z1}}(\xi)=\mathrm{H}_{11}(\xi)+\mathrm{H}_{12}(\xi)$

$\mathrm{H}_{\mathrm{z} 1}(\xi)=\mathrm{H}_{\text {core }}(\xi)=\frac{1}{\xi}\left[\mathrm{CJ}_{1}\left(\mathrm{U}_{\mathrm{i}} \mathrm{d} \xi\right)+\mathrm{D} \mathrm{Y}_{1}\left(\mathrm{U}_{\mathrm{i}} \mathrm{d} \xi\right)\right]$

Where,

$\mathrm{U}_{\mathrm{i}}{ }^{2}=\mathrm{k}_{0}{ }^{2} \mathrm{n}_{\mathrm{i}}^{2}-\beta^{2}$

For $i=1,2$ the corresponding refractive indices are $n_{1}$ and $n_{2}$. Again we can have the solution for core region and the outmost part as

$\mathrm{E}_{\mathrm{z} 2}(\xi)=\frac{1}{\xi}\left[\mathrm{EI}_{1}(\mathrm{wd} \xi)+\mathrm{FK}_{1}(\mathrm{wd} \xi)\right]$,

$\mathrm{E}_{\mathrm{z} 2}(\xi)=\mathrm{E}_{\text {cladd }}(\xi)$

(for cladding)

$\mathrm{H}_{\mathrm{z} 2}(\xi)=\frac{1}{\xi}\left[\mathrm{GI}_{1}(\mathrm{wd} \xi)+\mathrm{HK}_{1}(\mathrm{wd} \xi)\right]$,

$\mathrm{H}_{\mathrm{z} 2}(\xi)=\mathrm{H}_{\text {cladd }}(\xi)$

Where, $w=\sqrt{\beta^{2}-k_{0}^{2} n_{c}^{2},}$

$\mathrm{n}_{\mathrm{C}}$ - common refractive index .

$\mathrm{J}_{\mathrm{n}}$ - Bessel functions of first kind.

$Y_{n}$ - Bessel functions of second kind.

$\mathrm{I}_{\mathrm{n}} \& \mathrm{~K}_{\mathrm{n}}$ - modified Bessel functions.

$\beta$ - Axial component of propagation vector.

$\omega$ - Wave frequency.

$\mu$-permeability of non-magnetic medium

$\varepsilon_{1}$ - permittivity of the core.

$\varepsilon_{2}$ - permittivity of the cladding region

$\mathrm{d}=(\sqrt{ } 2)^{2}$

A, B, C, D, E, F, G and $\mathrm{H}$ are all constants and these are unknown.

Boundary conditions for the above Bragg waveguide consideration is

$$
\begin{aligned}
\left.\mathrm{E}_{\text {core }}(\xi)\right|_{\mathrm{m}} & =\left.\mathrm{E}_{\text {cladd }}(\xi)\right|_{\mathrm{mi}}, \\
\left.\frac{\partial \mathrm{E}(\xi)}{\partial \xi}\right|_{\mathrm{m}} & =\left.\frac{\partial \mathrm{E}(\xi)}{\partial \xi}\right|_{\mathrm{mi}} .
\end{aligned}
$$

By analytically solving this equation we get equations which contain twenty two unknown constants. Then we put in a $12 \times 12$ matrix[2].The determinant formed by this matrix is $\operatorname{det}[\mathrm{i}]$.We can get the nontrivial solution only when

$$
\operatorname{det}[i]=0 \text {. }
$$

\subsection{Dispersion}

We have the general equation for normalized propagation constant,

$$
\mathrm{b}=\left(\beta^{2} / \mathrm{k}_{0}^{2}-\mathrm{n}_{1}^{2}\right) /\left(\mathrm{n}_{\mathrm{c}}^{2}-\mathrm{n}_{1}^{2}\right),
$$

Where, values of $\beta$ lying between $n_{c} k_{0}$ and $n_{1} k_{0}$.

$\mathrm{n}_{\mathrm{c}}$ - Refractive index of the core.

$\mathrm{n}_{1}$ - Refractive index of the cladding .

Since, $\beta / \mathrm{k}_{0} \approx \mathrm{n}_{\mathrm{c}}$ for the region which is far from the cutoff.

$$
\mathrm{b} \approx\left(\beta / \mathrm{k}_{0}-\mathrm{n}_{1}\right) /\left(\mathrm{n}_{\mathrm{c}}-\mathrm{n}_{1}\right) .
$$

Similarly, cut-off frequency,

$$
\begin{gathered}
\mathrm{V}=\frac{2 \pi}{\lambda} \mathrm{p}_{0}\left(\mathrm{n}_{\mathrm{c}}^{2}-\mathrm{n}_{1}^{2}\right)^{1 / 2}, \\
\mathrm{~V}=\frac{2 \pi}{\lambda} \mathrm{p}_{0} \mathrm{NA}
\end{gathered}
$$

But here, for our proposed waveguide geometry the equation for cut-off frequency and normalized propagation constant can be modified as,

$$
\begin{aligned}
& \mathrm{V}=\mathrm{k}_{0}\left(\mathrm{p}_{0}-\mathrm{p}_{1}\right)\left(\mathrm{n}_{1}^{2}-\mathrm{n}_{\mathrm{c}}{ }^{2}\right)^{1 / 2} \\
& \approx \mathrm{k}_{0}\left(\mathrm{p}_{0}-\mathrm{p}_{1}\right)\left[2 \mathrm{n}\left(\mathrm{q}+\mathrm{q}^{\prime}\right)\right]^{1 / 2} .
\end{aligned}
$$

Where

$$
\begin{aligned}
& \mathrm{q}=\mathrm{n}_{1}-\mathrm{n}_{2} \text {, } \\
& \mathrm{q}^{\prime}=\mathrm{n}_{1-} \mathrm{n}_{\mathrm{c}} \text {, } \\
& \mathrm{k}_{0} \text { - vacuum wave number. } \\
& \mathrm{k}_{0}=\frac{2 \pi}{\lambda} \text {, } \\
& \mathrm{b}=\beta^{2}-\mathrm{k}_{0}{ }^{2} \mathrm{n}_{\mathrm{c}}{ }^{2} / \mathrm{k}_{0}{ }^{2}\left(\mathrm{n}_{1}{ }^{2}-\mathrm{n}_{\mathrm{c}}{ }^{2}\right) \\
& \approx \beta-\mathrm{k}_{0} \mathrm{n}_{\mathrm{c}} / \mathrm{k}_{0}\left(\mathrm{q}+\mathrm{q}^{\prime}\right)
\end{aligned}
$$

We can write the expression for the normalized

(for weak guidance consideration)

The parameter $\mathrm{V}$ i.e. the cutoff frequency is a dimensionless parameter. The other parameters that we have considered here $\mathrm{n}_{\mathrm{c}}, \mathrm{n}_{1}, \mathrm{p}_{0}, \mathrm{p}_{1}$ and $\mathrm{k}_{0}$ that may have an effect on propagation. There are also different alternative procedure to define the cutoff frequency $\mathrm{V}$ and normalized propagation constant $b$. 


\subsection{Intermodal Dispersion Calculation}

The equation for Intermodal dispersion [14] in multimode propagation,

$$
\begin{aligned}
\Delta \mathrm{T} & =\left(\mathrm{L} / 2 \mathrm{n}_{\mathrm{c}} \mathrm{c}\right)\left(\mathrm{n}_{\mathrm{c}}{ }^{2}-\mathrm{n}_{1}{ }^{2}\right)^{2} \\
& =\left(\mathrm{L} / 2 \mathrm{n}_{\mathrm{c}} \mathrm{c}\right)(\mathrm{NA})^{2},
\end{aligned}
$$

Where,

c - Speed of light

L- Length of the fiber considered.

For our unconventional Bragg waveguide consideration if we take $\mathrm{n}_{\mathrm{c}}=1.0002, \mathrm{n}_{1}=1.45$ and $\mathrm{c}=3 \times 10^{8}$ then we can calculate

$$
\Delta \mathrm{T}=-1.83 \times 10^{-9} \mathrm{~L}
$$

Again for conventional case if we take $\mathrm{n}_{\mathrm{c}}=1.45, \mathrm{n}_{1}$ $=1.0002$.

$$
\Delta \mathrm{T}=1.26 \times 10^{-9} \mathrm{~L}
$$

For a particular length $\mathrm{L}$ we have calculated the dispersion and analyze that in the sense of dispersion this Bragg waveguides shows good performance compared to the conventional one.

\subsection{Power Loss}

Ratio of power through the cladding to the total power [14] is

$$
\begin{gathered}
\frac{\mathrm{Pc}}{\mathrm{Pt}}=\frac{4}{3} \mathrm{M}^{-1 / 2} \\
\mathrm{M}=\mathrm{V}^{2} / 2
\end{gathered}
$$

From this equation we can analyze that power loss in the present consideration totally depends on the diameter of the core considered. For higher core diameter the power loss is less.

\subsection{Group Velocity Consideration}

We have,

$$
\mathrm{V}_{\min }=\mathrm{c}\left(\mathrm{n}_{1} / \mathrm{n}_{\mathrm{c}}\right), \quad \mathrm{V}_{\max }=\mathrm{c}
$$

From this we can analyze that the minimum group velocity $\left(\mathrm{V}_{\mathrm{min}}\right)$ [14] for our Bragg waveguide consideration is higher in compared to any conventional fiber. As a result the transmission is faster.

\subsection{Response Time}

$$
\sigma \approx \frac{\mathrm{L}}{\mathrm{c}} \frac{\Delta}{2}(41)
$$

Where,

$$
\Delta=\left(\mathrm{n}_{\mathrm{c}}-\mathrm{n}_{1}\right) / \mathrm{n}_{\mathrm{c}}
$$

i.e. From this expression we can observe that here the response time [14] is less compared to the conventional fibers.

\subsection{Pulse broadening Rate(Pbr)}

$$
\mathrm{Pbr} \approx\left(\mathrm{n}_{\mathrm{c}} \Delta^{2}\right) / 4 \mathrm{c}
$$

i.e. for this Bragg waveguide consideration pulse broadening rate [14] is less as a consequence there is less possibility of interference.

\section{Numerical Analysis}

The mathematical analyses are shown above for hypocycloidal and elliptical Bragg waveguide respectively. That gives us relevant information's in case of the modal dispersion of the considered Bragg waveguides. The equation (37) gives the expression for the dimensionless parameter $\mathrm{V}$.In the same way equation (38) gives the expression for the dimensionless parameter $b$ for our Bragg waveguide consideration. Then we have considered $\mathrm{n}_{\mathrm{c}}=$ 1.00004, $\mathrm{n}_{1}=1.35, \mathrm{n}_{2}=1.40, \mathrm{p}_{1}=0.01 \mu \mathrm{m}, 0.1 \mu \mathrm{m}, 1.0 \mu \mathrm{m}$ and $2 \mu \mathrm{m}, \lambda_{0}=1.55 \mu \mathrm{m}$ and for other values of $\mathrm{p}_{0}$ The values of $\mathrm{p}_{0}$ are changed in ar increasing order to exemplify eq(33) and (21). At first, for a particular value of $\mathrm{p}_{0}$ we are trying to calculate the left hand side of eq.(33) \& eq.(21). Which is for various values of $\beta$ that lies between $\mathrm{k}_{0} \mathrm{n}_{1} \& \mathrm{k}_{0} \mathrm{n}_{2}$. We have plotted the results of the left hand side of the Eq. (33) with respect to $\beta$.From this we get a graph, the graph intersects the $\beta=0$ axis at a point and we considered that point as the value of $\beta$ for the guided modes. By putting the $\beta$ values eq(38) we can get the value $b$. Similarly, By putting different value of $\mathrm{p}_{0}$ in eq(37) we can get the cutoff frequency $\mathrm{V}$. After that we have plotted the $b$ against $\mathrm{V}$. Then we get the dispersion curves for the considered Bragg waveguide.

\section{Results and Discussion}

The results are shown in the form of dispersion Curves below,

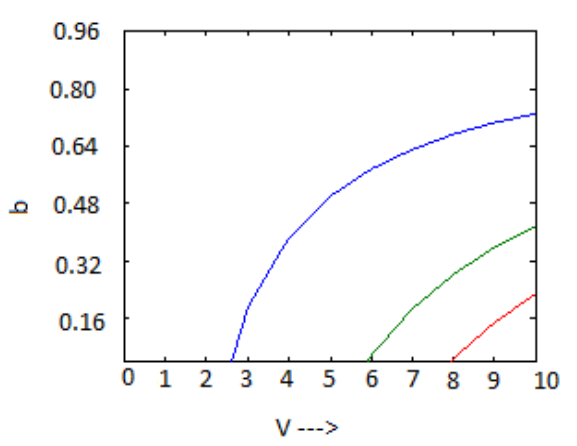

Fig 2. Cutoff frequency $V$ vs Normalized propagation constant $b$ for the six-layered Cladding (hypocycloidal Bragg waveguide) considering thickness $p_{1}=0.01 \mu \mathrm{m}$ 


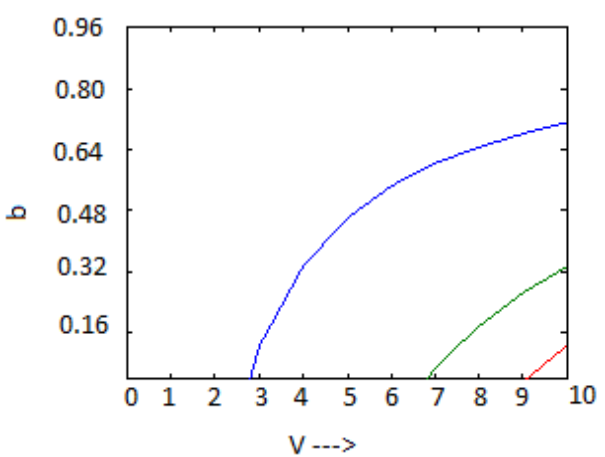

Fig 3. Cutoff frequency V vs. Normalized propagation constant $b$ for the four-layered cladding (hypocycloidal Bragg waveguide) considering thickness $p_{1}=0.01 \mu \mathrm{m}$

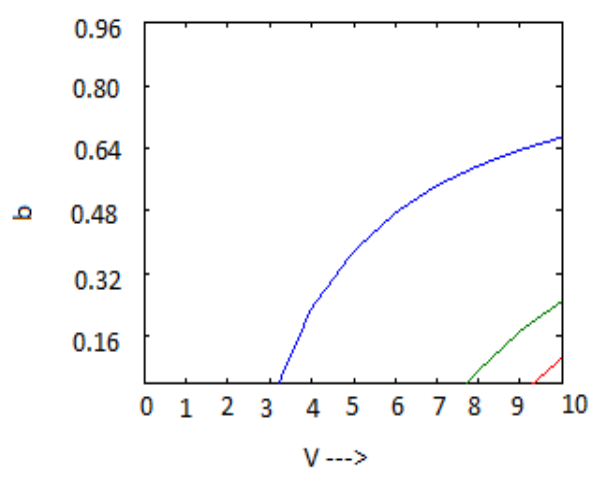

Fig 4. Cutoff frequency $V$ vs Normalized propagation constant $b$ for the two-layered Cladding (hypocycloidal Bragg waveguide) considering thickness $p_{1}=0.01 \mu \mathrm{m}$

For hypocycloidal Bragg waveguide dispersion curves are shown above from Fig.2 to Fig.4 for thickness of $\mathrm{p}_{1}=0.01 \mu \mathrm{m}$. Here, we can analyze from the figures that the cutoff frequencies of lowest order modes are $\mathrm{V}=2.6, \mathrm{~V}$ $=2.8$ and $\mathrm{V}=3.2$ respectively. For the thickness of $\mathrm{p}_{1}=0.1 \mu \mathrm{m}$ the cutoff frequencies for lowest order modes are $\mathrm{V}=3.7, \mathrm{~V}$ $=4.5$ and $\mathrm{V}=4.7$ respectively. From this we can infer that with the increase of thickness the cutoff frequency also increases. Again we can analyzed from the table that the cutoff frequencies increases for both from six layered to four layered and from four layered to two layered. Similarly, we get the cutoff frequencies for higher order modes which are shown in Table.1.

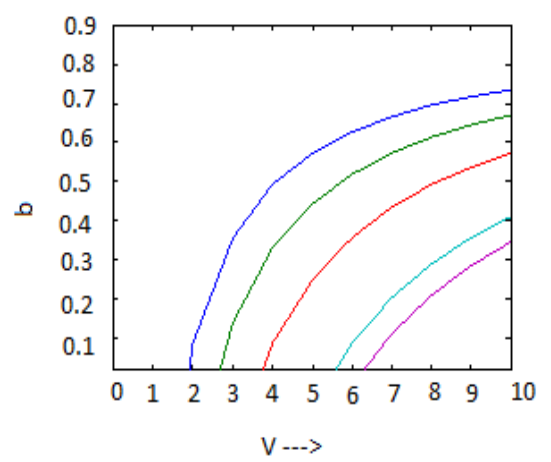

Fig 5. Cutoff frequency Vvs Normalized propagation constant $b$ for the Two-layered Cladding (elliptical Bragg waveguide) considering thickness $p_{1}=0.01 \mu \mathrm{m}$

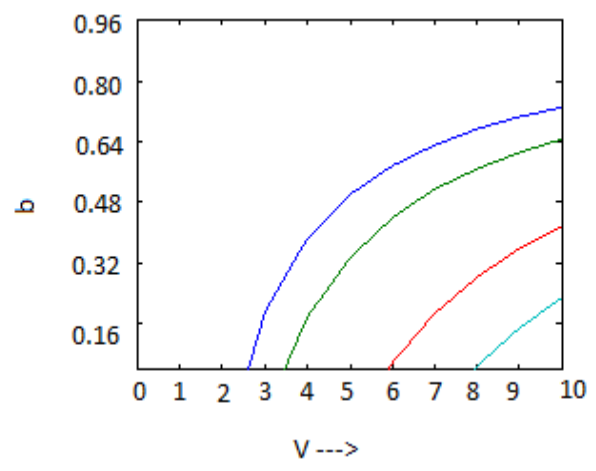

Fig 6. Cutoff frequency V vs Normalized propagation constant b for the four-layered cladding (elliptical Bragg waveguide) considering thickness $p_{I}=0.01 \mu \mathrm{m}$

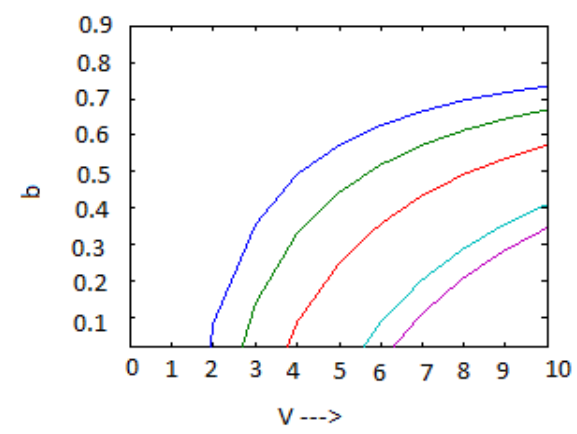

Fig 7. Cutoff frequency $V$ vs. Normalized propagation constant $b$ for the six-layered cladding (elliptical Bragg waveguide) considering thickness $p_{1}=0.01 \mu \mathrm{m}$

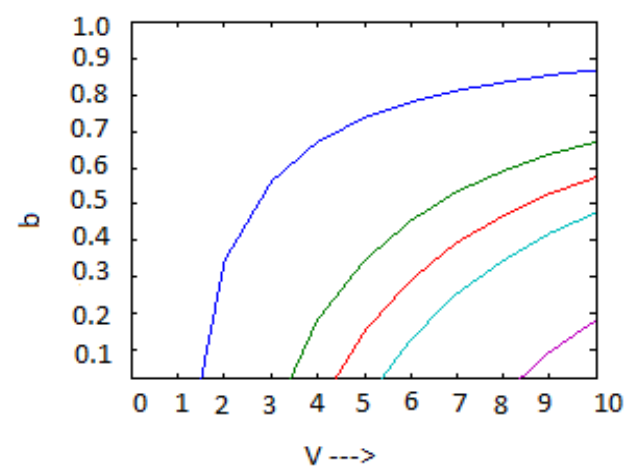

Fig 8. Cutoff frequency $V$ vs Normalized propagation constant $b$ for the two-layered cladding (elliptical Bragg waveguide) considering thickness $p_{1}=0.1 \mu \mathrm{m}$

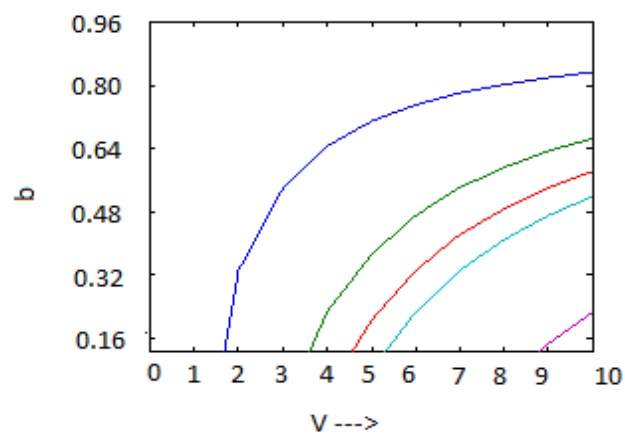

Fig 9. Cutoff frequency Vvs Normalized propagation constant $b$ for the four-layered Cladding (elliptical Bragg waveguide) considering thickness $p_{1}=0.1 \mu$ 


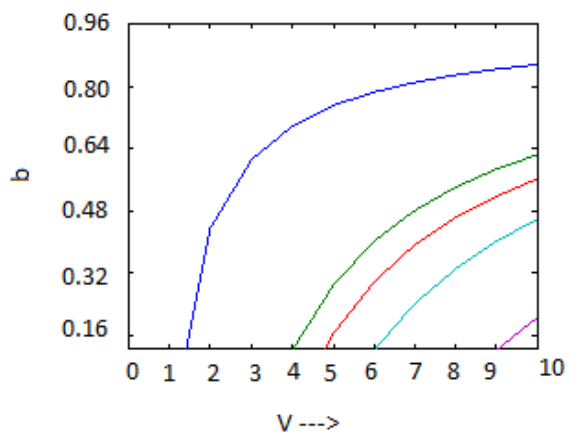

Fig 10. Cutoff frequency V vs. Normalized propagation constant $b$ for the four-layered cladding (elliptical Bragg waveguide) considering for thickness $p=1 \mu \mathrm{m}$

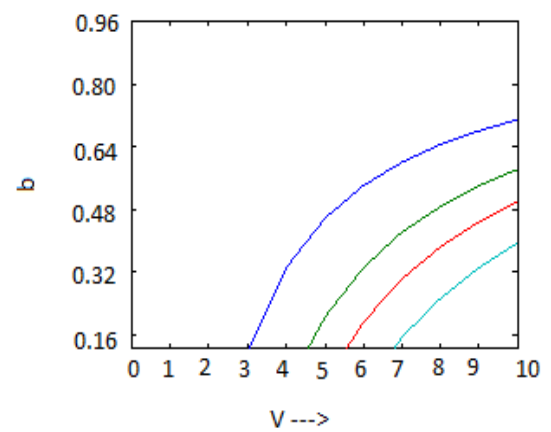

Fig 11. Cutoff frequency $V$ vs Normalized propagation constant $b$ for the six-layered cladding (elliptical Bragg waveguide) considering thickness $p_{1}=1 \mu \mathrm{m}$

For elliptical Bragg waveguide some dispersion curves are shown above from Fig.5 to Fig.11.For thickness of $\mathrm{p}_{1}=0.01 \mu \mathrm{m}$ the dispersion curves for two layered, four layered and six layered cladding are shown from Fig.5 to Fig.7 respectively.. Here, we can analyze from the figures that the cutoff frequencies of lowest order modes are $\mathrm{V}$ $=1.9, \mathrm{~V}=2.6$ and $\mathrm{V}=1.0$ respectively. For the thickness of $\mathrm{p}_{1}=0.1 \mu \mathrm{m}$ the cutoff frequencies for lowest order modes are $\mathrm{V}=1.0, \mathrm{~V}=416$ and $\mathrm{V}=1.3$ respectively. From this we can infer that with the increase of thickness the cutoff frequency decreases. The same case is also happening in case of higher order modes. Again we can analyze from Table.2 that the cutoff frequencies increases form six layered to four layered but from four layered to two layered it become decreases. Similarly, we get the cutoff frequencies for higher order modes which are shown in Table.2

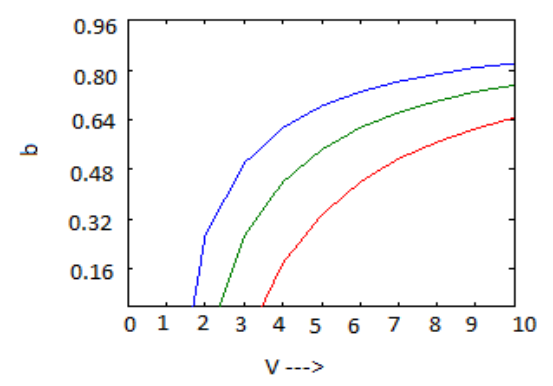

Fig 12. Cutoff frequency Vvs. Normalized propagation constant $b$ for the six-layered cladding (hypocycloidal Bragg waveguide) considering thickness $p_{I}=2 \mu \mathrm{m}$

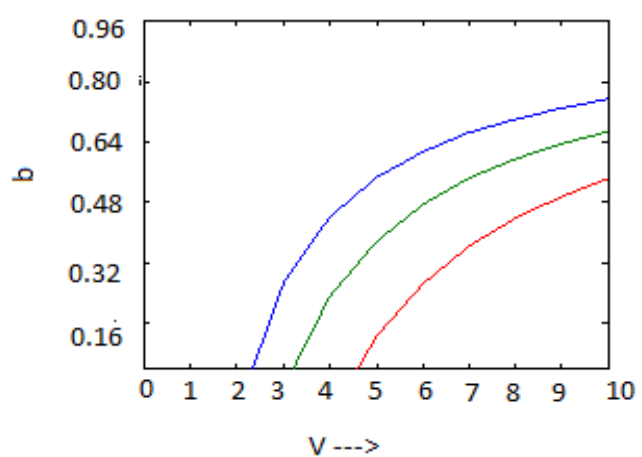

Fig 13. Cutoff frequency $V$ vs Normalized propagation constant $b$ for the four-layered cladding (hypocycloidal Bragg waveguide) considering thickness $p_{I}=2 \mu \mathrm{m}$

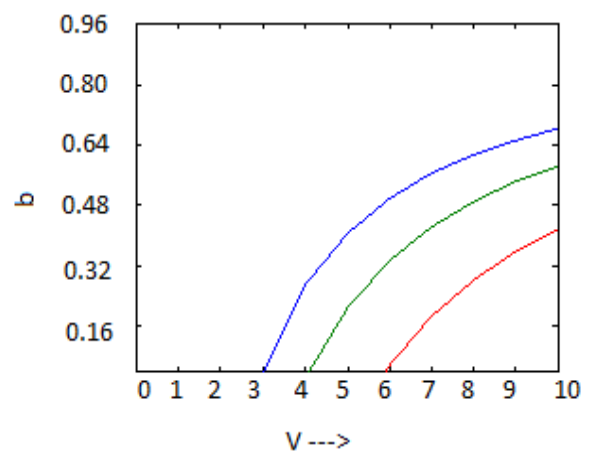

Fig 14. Cutoff frequency $V$ vs Normalized propagation constant $b$ for the two-layered Cladding (hypocycloidal Bragg waveguide) considering thickness $p_{I}=2 \mu \mathrm{m}$

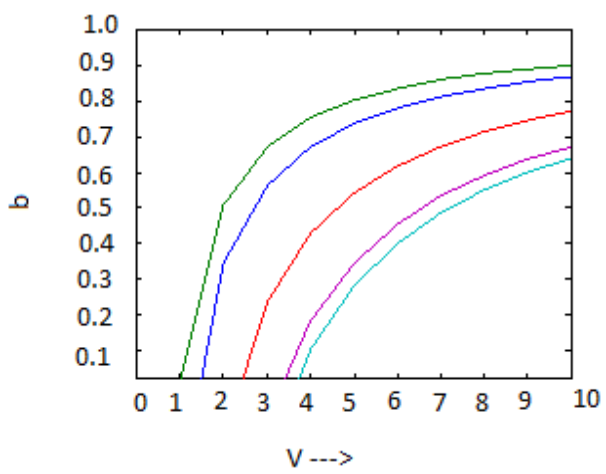

Fig 15. Cutoff frequency Vvs. Normalized propagation constant $b$ for the six-layered cladding (elliptical Bragg waveguide), considering thickness $p_{1}=2 \mu \mathrm{m}$

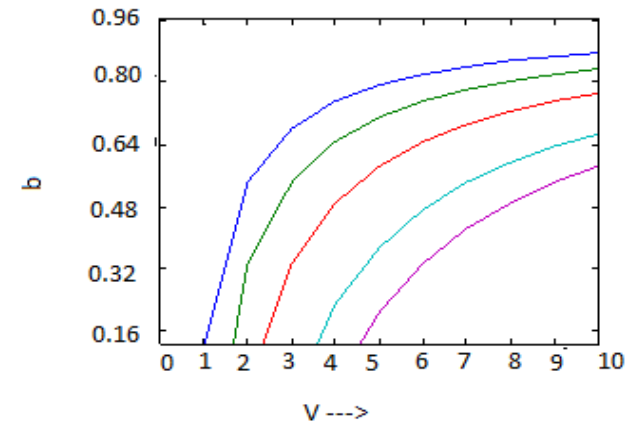

Fig 16. Cutoff frequency $V$ vs Normalized propagation constant $b$ for the four-layered cladding (elliptical Bragg waveguide) considering thickness $p_{l}=2 \mu \mathrm{m}$ 


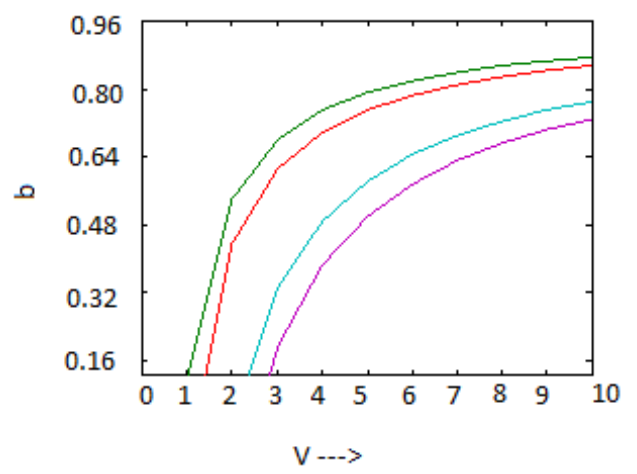

Fig.17. Cutoff frequency $V$ vs. Normalized propagation constant $b$ for the two-layered cladding (elliptical Bragg waveguide), considering thickness $p_{I}=2 \mu \mathrm{m}$

\subsection{Analysis from Dispersion Curves for $p_{1}=2 \mu m$}

For a thickness of $\mathrm{p}_{1}=2 \mu \mathrm{m}$, the dispersion curves for hypocycloidal Bragg waveguide are shown from Fig.12 to Fig.14.We have analyzed that for LP12 mode the cutoff frequencies are $\mathrm{V}=2.21, \mathrm{~V}=3.2$ and $\mathrm{V}=4.1$ respectively. So we can infer that for this thickness, this Bragg waveguide retains the same property, where cutoff frequencies increases for both six layered to four layered and from four layered to two layered. The other interesting point that we have analyzed is that for this thickness the cutoff frequencies are become less compared to the previous thicknesses considered. Results are shown in Table.3.

Again, for a thickness of $\mathrm{p}_{1}=2 \mu \mathrm{m}$, the dispersion curves for elliptical Bragg waveguide are shown from Fig. 15 to Fig. 17. We have analyzed that for LP12 mode the cutoff frequencies are $\mathrm{V}=1.42, \mathrm{~V}=1.6$ and $\mathrm{V}=1.25$ respectively. So we can infer that for this thickness, this Bragg waveguide retains the same property, where cutoff frequencies increases for six layered to four layered and from four layered to two layered it becomes decreases. But here we got an exception for the lowest order mode where the cut off frequencies are $\mathrm{V}=1.0, \mathrm{~V}=1.0$ and $\mathrm{V}=1.0$ respectively. Results are shown in Table.3.

For hypocycloidal Bragg waveguide with a thickness of $1 \mu \mathrm{m}$ we have seen that in case of six-layered as well as in four-layered curves are not coming in an observable way. So we can infer that transmission of information in both this cases is not reliable because there is possibility of losing information

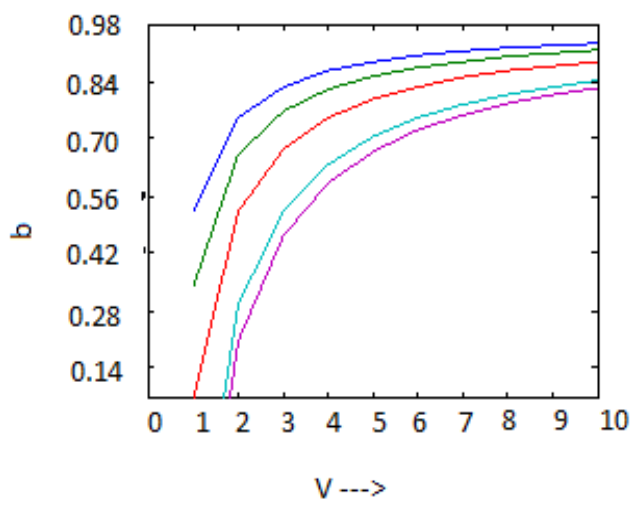

Fig 18. Cutoff frequency $V$ vs Normalized propagation constant $b$ for the six-layered Cladding (hypocycloidal Bragg waveguide)for thickness $1 \mu \mathrm{m}$

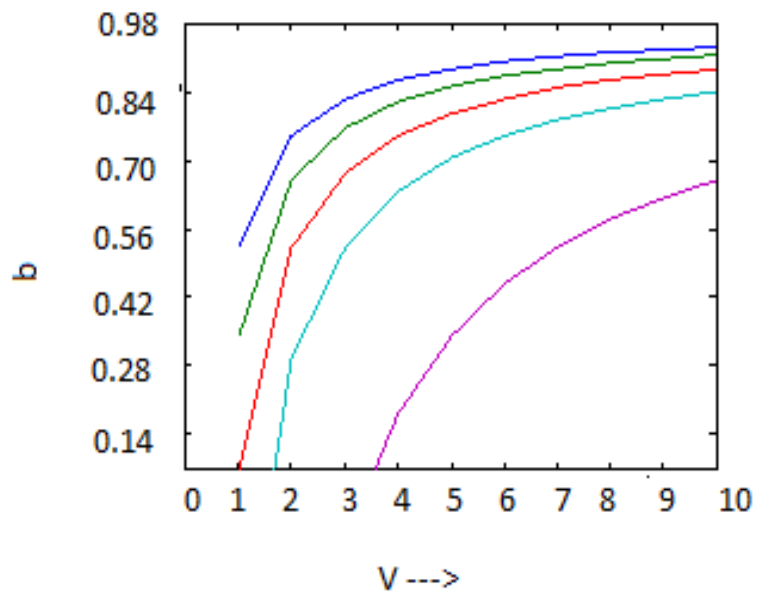

Fig 19. Cutoff frequency $V$ vs Normalized propagation constant $b$ for the four-layered Cladding (hypocycloidal Bragg waveguide)for thickness $1 \mu \mathrm{m}$

Table 1. For hypocycloidal Bragg fiber the Cutoff frequencies are given below for various modes considering thicknesses $p_{I}=0.01 \mu m, p_{I}=0.10 \mu m$ and $p_{1}=1.00 \mu m$.

\begin{tabular}{|c|c|c|c|c|c|c|c|c|c|}
\hline \multirow{2}{*}{$\begin{array}{c}\begin{array}{c}\text { Mode } \\
\text { No. }\end{array} \\
\text { LP1m }\end{array}$} & \multicolumn{3}{|c|}{$\begin{array}{c}\text { Cutoff frequencies for thickness of } \\
\mathrm{p}_{1}=0.01 \mu \mathrm{m} \text { in hypocycloidal Bragg fiber } \\
0<\mathrm{V}<10\end{array}$} & \multicolumn{3}{|c|}{$\begin{array}{c}\text { Cutoff frequencies for thickness of } \\
\mathrm{p}_{1}=0.1 \mu \mathrm{m} \text { in hypocycloidal Bragg fiber } \\
\qquad 0<\mathrm{V}<10\end{array}$} & \multicolumn{3}{|c|}{$\begin{array}{l}\text { Cutoff frequencies for thickness of } \\
p_{1}=1 \mu \mathrm{m} \text { in hypocycloidal Bragg fiber } \\
\qquad 0<\mathrm{V}<10\end{array}$} \\
\hline & $\begin{array}{c}6 \\
\text { (layered) }\end{array}$ & $\begin{array}{c}4 \\
\text { (layered) }\end{array}$ & $\begin{array}{c}2 \\
\text { (layered) }\end{array}$ & $\begin{array}{c}6 \\
\text { (layered) }\end{array}$ & $\begin{array}{c}4 \\
\text { (layered) }\end{array}$ & $\begin{array}{c}2 \\
\text { (layered) }\end{array}$ & $\begin{array}{c}6 \\
\text { (layered) }\end{array}$ & $\begin{array}{c}4 \\
\text { (layered) }\end{array}$ & $\begin{array}{c}2 \\
\text { (layered) }\end{array}$ \\
\hline LP11 & 2.6 & 2.8 & 3.2 & 3.7 & 4.5 & 4.7 & - & - & 2.38 \\
\hline LP12 & 5.8 & 6.8 & 7.8 & 8.6 & 9.2 & 9.42 & - & 0.0 & 4.9 \\
\hline LP13 & 7.9 & 9.1 & 9.26 & 9.2 & 9.4 & 9.7 & 1.1 & 1.9 & 7.1 \\
\hline LP14 & - & - & - & - & - & - & 1.8 & 3.7 & - \\
\hline LP15 & & - & & & - & & & - & \\
\hline
\end{tabular}


Table 2. For elliptical Bragg fiber the Cutoff frequencies are given below for various modes considering thicknesses $p_{I}=0.01 \mu m, p_{I}=0.10 \mu m$ and $p_{1}=1.00 \mu \mathrm{m}$.

\begin{tabular}{|c|c|c|c|c|c|c|c|c|c|}
\hline \multirow{2}{*}{$\begin{array}{c}\begin{array}{c}\text { Mode } \\
\text { No. }\end{array} \\
\text { LP1m }\end{array}$} & \multicolumn{3}{|c|}{$\begin{array}{l}\text { Cutoff frequencies for thickness of } \\
p_{1}=0.01 \mu \mathrm{m} \text { in elliptical Bragg fiber } \\
\qquad 0<\mathrm{V}<10\end{array}$} & \multicolumn{3}{|c|}{$\begin{array}{l}\text { Cutoff frequencies for thickness of } \\
p_{1}=0.1 \mu \mathrm{m} \text { in elliptical Bragg fiber } \\
\qquad 0<\mathrm{V}<10\end{array}$} & \multicolumn{3}{|c|}{ 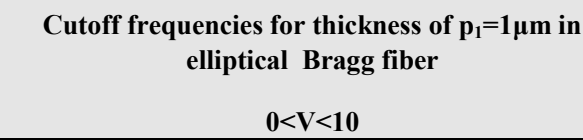 } \\
\hline & $\begin{array}{c}6 \\
\text { (layered) }\end{array}$ & $\begin{array}{c}4 \\
\text { (layered) }\end{array}$ & $\begin{array}{c}2 \\
\text { (layered) }\end{array}$ & $\begin{array}{c}6 \\
\text { (layered) }\end{array}$ & $\begin{array}{c}4 \\
\text { (layered) }\end{array}$ & $\begin{array}{c}2 \\
\text { (layered) }\end{array}$ & $\begin{array}{c}6 \\
\text { (layered) }\end{array}$ & $\begin{array}{c}4 \\
\text { (layered) }\end{array}$ & $\begin{array}{c}2 \\
\text { (layered) }\end{array}$ \\
\hline LP11 & 1.9 & 2.6 & 1.0 & 1.0 & 1.6 & 1.3 & & 1.21 & 4.7 \\
\hline LP12 & 2.6 & 3.5 & 1.8 & 2.6 & 3.63 & 3.3 & 3.0 & 3.92 & 3.64 \\
\hline LP13 & 3.8 & 5.8 & 2.4 & 3.5 & 4.46 & 4.25 & 4.5 & 4.7 & 8.26 \\
\hline LP14 & 5.6 & 7.9 & 3.3 & 5.0 & 5.3 & 5.18 & 5.2 & 6.1 & 9.2 \\
\hline LP15 & 6.3 & & 5.0 & 7.4 & 8.8 & 8.2 & 6.8 & 9.11 & \\
\hline LP16 & - & & & - & & & - & & - \\
\hline LP17 & - & & & - & & & - & - & - \\
\hline
\end{tabular}

Table 3. For elliptical Bragg fiber and hypocycloidal Bragg fiber the Cutoff frequencies are given below for various modes considering thicknesses $p_{l}=2 \mu m$.

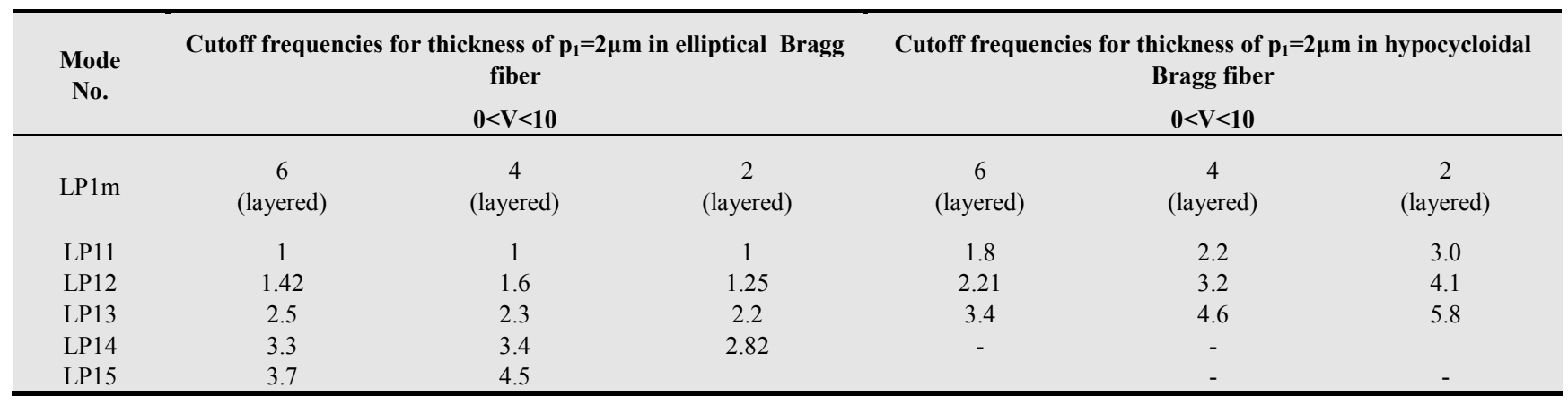

\section{Conclusion}

We find the interesting feature that for thickness $\mathrm{p}_{1}=0.01 \mu \mathrm{m}$ and for $\mathrm{V} \leq 10.0$ for the different cladding layer consideration the hypocycloidal Bragg waveguide can sustain a single mode only. This shows that this Bragg waveguide with less number of claddings shows comparatively better performance than other Bragg fiber. In addition to that in this Bragg waveguide the absorption of energy is very less. From the analysis we can also infer that this Bragg waveguide sustains less number of modes compared to the elliptical Bragg waveguide.

It is also observed that in case of hypocycloidal Bragg waveguide the cutoff frequency of some modes are greater compared to the elliptical Bragg waveguide. But in one or two case there is exception also observed. As a result hypocycloidal Bragg waveguide sustains less number of modes in compared to the elliptical Bragg waveguide. Because greater the Cutoff frequency corresponds to the less number of modes sustain. For the elliptical Bragg waveguide consideration we can infer that when the cladding layer decreases from six-layer to four layers the cutoff values increases. But when it goes from four layers to two layers the cutoff values become decreases. The disadvantage of elliptical Bragg waveguide is that this structure is more complicated compared to the hypocycloidal in case of greater thickness and higher number of cladding layers.
The analysis has been done by the authors in [1] on hypocycloidal Bragg waveguide for thicknesses $p_{1}=0.01$ $\mu \mathrm{m}, 0.1 \mu \mathrm{m}$ and $1 \mu \mathrm{m}$. Based on their analysis in this paper we are also trying to observe the cut-off values for higher thickness values. We observed that if we increase the thickness to $p_{1}=2 \mu \mathrm{m}$, then it also follows the same property for different layers but the cutoff frequency values are lower compared to the other thicknesses considered above. Similarly, based on [2], in this paper we are trying to observe the cut-off values for higher thickness values It is observed that when the thickness is increase to $p_{1}=2 \mu \mathrm{m}$, then it also retains the same property for different layers but the cutoff frequency values are lower compared to the other thicknesses considered.

\section{Reference}

[1] V. singh, Y. Prajapati, J. P. Saini, Modal analysis and dispersion curves of a new unconventional Bragg waveguide using a very simple method, Progress in Electromagnetic Research, PIER 64,191-204,2006.

[2] Y. Prajapati, Vivek Singh, J.P.Saini, Modal analysis of a super-elliptical Bragg waveguide with a small number of periodic cladding layers based on a very simple analytical technology, Optic 120(2009) 14-19.

[3] Singh, V., B. Prasad, and S. P. Ojha, Analysis of the modal characteristics of a Bragg fiber with a small number of claddings using a very simple analytical method, Microwave Opt. Techncol Letter, vol. 46, 271-275, 2005. 
[4] Yeh, P. and A. Yariv, Theory of Bragg fiber, J.opt Soc. Am, Vol. 68, 1196-1201, 1978.

[5] Scalora, M., et al., Optical limiting and switching of ultra short pulses in non-linear photonic band gap materials, Phys. Rev. Lett., Vol. 73, 1368-1371, 1994.

[6] Chigrin, D. N., et al.,A dielectric Bragg mirror: Can it be an Omni directional reflector?, Optics and Photonics News, Optics, Vol. 10, 33, 1999.

[7] Yablonovitch, E., Inhibited spontaneous emission in solid state physics and electronics, Phys. Rev. Lett., Vol. 58, 2059-2062, 1987.

[8] Joannopoulos, J. D., et al., Photonic Crystals: Molding the Flow of Light, Princeton Univ. Press, N.J. 1995.

[9] Dasgupta,S.,B. P. Pal, and M. R. Shenoy, Bragg Fibers: Guided wave optical components and devices, B. P. Pal (ed.), Elsevier, IIT Delhi, India, 2005.
[10] Ito, H. T. N., Y. Sabaki, H. Ohtsu, K. I. Lee, and W. Jhe, Phys. Rev. Lett., Vol. 76, 4500, 1995.

[11] Bassett, I. M. and A. Arggros, Elimination of polarization degeneracy in round waveguides, Optics Express, Vol. 10, $1342-1346,2002$

[12] Singh, V., B. Prasad, and S. P. Ojha, A comparative study of the modal characteristics and wave guide dispersion of optical waveguides with three different closed loop cross sectional boundaries, Optik, Vol. 115, 281-288, 2004.

[13] Singh, V., B. Prasad, and S. P. Ojha, Theoretically obtained dispersion characteristics of an annular waveguide with a guiding region cross section bounded by two hypocycloidal loops Microwave Opt. Techncol Letter, Vol. 37, 142-145, 2003.

[14] A. Ghatak, K,Thyagarajan, Introduction to fiber optics, Cambridge University press,Cambridge, 1998 p.141 